\title{
Wastewater Management, Recycling and Discharge
}

\author{
Akpor O. B. ${ }^{1, ~ *}$, Kayode-Oni O. $\mathbf{I}^{1}$., Babalola O. O. ${ }^{2}$ \\ ${ }^{1}$ Department of Biological Sciences, Landmark University, Omu-Aran, Kwara State, Nigeria \\ ${ }^{2}$ Department of Science Technology, Federal Polytechnic, Ado Ekiti, Nigeria
}

Email address:

akpor.oghenerobor@1mu.edu.ng (Akpor O. B.)

\section{To cite this article:}

Akpor O. B., Kayode-Oni O. I., Babalola O. O. Wastewater Management, Recycling and Discharge. Hydrology.

Vol. 3, No. 3, 2015, pp. 33-37. doi: 10.11648/j.hyd.20150303.11

\begin{abstract}
This paper was aimed at reviewing the management, discharge and recycling of wastewater. In addition, the challenges and remediation processes for wastewater discharge were also discussed. Water is a substance of great importance to humans, animals and plants. Although a larger part of the earth is covered by water, its use has always been limited in terms of availability, quality and quantity. Water treatments are mainly for the removal of waste product from water in such a way that it can meet the standard for consumption. Environmental sustainability entails making decisions and actions in the relevance of protecting the natural world, with importance of preserving the competency of the environment to support human life. The increasing discharge of wastewater due to increase in population has led to the deterioration of the environment and threat to human health. Wastewater reuse is important in the irrigation of agricultural areas cause of the maintenance of water reservoirs and plants with nutrient which makes the request for fertilizers low. Generally of the considerable developments in water reuse have occurred in waterless regions of the world. One of the most potential for water reprocess is to restore freshwater burden of industries. The method that helps to minimize the discharge of residuals such as recycling wastewater, remediation measures, environmental awareness and sewage pollution control.
\end{abstract}

Keywords: Wastewater Management, Sustainability, Wastewater Discharge, Water Quality

\section{Introduction}

Wastewater is any water whose quality and visual worth has been harmfully affected by anthropogenic influences. Wastewater is formed when water from a variety of sources is used to the extent that its quality is degraded and is generated mainly from domestic, industrial and agricultural sources. Generally, untreated wastewater may contain substances that are known to adversely degrade water quality [1]. The management of wastewater entails the collection and treatment of wastewater. It also involves the administration, financing, engineering, planning, designing, maintenance, monitoring and evaluation of overall performance of wastewater treatment systems [2].

Wastewater recycling, reclamation or reuse is the direct or indirect use of treated wastewater effluent for beneficial purposes. Recycled water can be used for agriculture, landscape, toilet flushing, public parks, artificial lakes and waterfalls, irrigation of golf courses, cooling water for power plants and refineries, dust control during road construction, concrete mixing, site clean-up and other construction activities. In industrial settings, recycled wastewater can be used onsite through recirculation [3]

The management of water solution has really been helped by recycling wastewater. Water recirculation, which is a form of wastewater recycling is a means of using the same water more than once in an industrial system [4]. Some of the advantages of recycled wastewater are decrease in the need to redirect freshwater from an already threatened ecosystem, sustainable and healthier aquatic ecosystems, decrease in the discharge of wastewater into sensitive water bodies thus preserving aquatic ecosystems, reduction and prevention of pollution since wastewater discharge into water bodies is reduced. However, before recycling or reusing wastewater, it is vital to first apply the required treatment that is tailored towards meeting the water quality requirement of planned reuse. For the removal of extensive amounts of particulate matter in treated effluents, improved treatment steps, such as disinfection and ultra-filtration are applied [5].

The discharge of wastewater is the process of disposing off or reintroducing wastewater into the environment. The commonest methods of discharge are surface dispersal (such as irrigation), subsurface discharge and dilution (disposal of wastewater into surface waters e.g. seas, lakes, estuaries and 
wetlands). When untreated wastewater is discharged into the environment, it poses environmental, aesthetic and health problems. In order to safeguard public health and sustain the environment, there are a number of regulations and effluent discharge guidelines that stipulate the minimum treatment levels and maximum limits of pollutants in a wastewater before it is discharged into receiving water bodies [6]. The aim of this paper was to review the management, discharge and recycling of wastewater. In addition, the challenges and remediation processes for wastewater discharge were also discussed.

\section{Water Resource Management and Environmental Sustainability}

Water is an essential natural resource that all social, economic and ecosystem activities depend on. Despite the importance of water to existence, the effect of climatic change on available water resources have caused major uncertainties on the amount of water that is required to meet demand for food, energy and other uses by human to sustain the ecosystem [7]. Because water is needed for sustainable economic development, there is the need for proper management where there is limited water resource. Proper management entails that water is allocated towards different uses in order to maintain the overall return made up by the advantages water provide through different developmental sector. This could help to improve and share various advantages in the society and economy [8].

Water is a substance of importance connected to animals, plants and humans. It is a product that is of useful quality and without it lives are being threatened. Although water is known to cover a large part of the earth, it is limited in terms of availability, quantity and quality [9]. Some of the problems of water management are limited resources, insufficient rainfall, fast growing population and dormant economies [10].

Despite the fact that freshwater is a universal resource, to ensure the long-lasting development of global freshwater needs, the general management of resources and appropriate knowledge of articulated elements related to freshwater and its quality are important [11]. Most problems of quality of various water bodies result from issues that affect variable order of importance, such as insufficient treated domestic sewage and controls on the discharges of industrial wastewater, loss and damage of catchment areas, careless sitting of industrial plants, deforestation, uncontrolled shift cultivation and poor agricultural practices [2].

In improving integrated water management, it is posited that the fragmentation of responsibilities for water resources development among sectoral agencies is a great impediment. A major issue for most water based resources in the future is the sustainability of the present and future water resource allocation. The sustainability of a water resource is important because as water becomes scarce, if not properly monitored, it grows vastly hence unable to meet the needs of humans and the environment. In order to avoid costly and desperate measures, efficient management of water should ensure there is measures to regenerate, develop and treat new water supplies [3].

It is indicated that the most significant goals of integrated water resource management are to preserve a water source that provides ideal benefits to the population. These benefits include satisfying their personal needs and leaving them to undergo socio economic activities without unnecessarily damaging the environment and helps influence the resource in a way that minimizes the impact of natural disasters. An appropriate integrated management ensures that there is integration among uses in order to guarantee continuing development [2]. A water resource is therefore managed to guarantee more dependable water availability and efficient water use in the agricultural sector, moderate flood damage, avoid development of soil salinity and water logging, control water pollution and reduce the easy spread of water-borne diseases.

It is worth mentioning that new methods and actions in different areas, such are water used efficiency, scarce water resource management and safe water quality management are needed to combat the evolving water predicament to both water quality and quantity. This will help to avoid setbacks in the allocation of water resources, manage efforts and establish guidelines and priorities for water allocation or pricing and order to avoid hindrance in the allocation of water resources [12].

Environmental sustainability is a structural multidimensional concept. At every level of revenue the connection between economic development and environmental sustainability is complex. In relation to water, sustainability ensures that the current and future generations have an adequate availability of water with suitable quality. Sustainability produces and preserves the conditions in which humans and nature can exist in productive harmony, thus fulfilling the social, economic and other necessities of current and future generations. In addition, sustainability assists in ensuring that water is continually available [13].

Environmental sustainability involves decision making and actions that are relevant to the protection of the natural world, with particular focus on preservation of the competency of the environment to support human life. Some of the environmental challenges to sustainability are development and industrialization, pollution and ecosystem damage. Other challenges include those that are due to underdevelopment and poverty, lack of financing in capital and arrangement dedicated to pollution control and ecosystem protection. Sustainability is not a stable endpoint that can be defined but a feature of active systems that maintain themselves overtime. It is long-term protection of valued environmental resources in an emerging human perspective [14].

Water quality guidelines are illustrative statements that are used to protect aquatic ecology and human water uses and values. When formulating guidelines, it is necessary to take into account cultural values that are indigenous. This is to ensure that conclusions that affect waterways protect these 
values and support intercultural understanding. Water quality guidelines assist in explaining the water quality needed to protect cultural values, healthy ecosystem and environmental values [15]. Guidelines provide a structure for accessing water quality on the basis of either physical, chemical or biological features. The limits for the determination of water quality by the planned use are the treatment of water for consumption, industrial use and environment [16].

Access to safe drinking water is based on two principles that include the control of substances that potentially affect human health and the control of visual qualities, taste, appearance and odour [17].

\section{Wastewater Reuse, Recycling and Discharge}

Wastewater is a major source of irrigation water in dry and semi-dry countries. During the $19^{\text {th }}$ century the release of wastewater into surface water bodies has led to the indirect use of wastewater and sewage into portable water supplies. Recycling is the reuse of wastewater in the same cycle it was generated while reuse is reutilization of wastewater. Wastewater recycling and reuse are very important in different areas and play special roles in the development of strategies for the consumption of water resources. Wastewater reuse is important in the irrigation of agricultural areas because of the maintenance of water reservoirs and plants with nutrient which makes the request for fertilizers low. For recreational purposes, sewage effluents with high quality are needed through the use of improved treatment steps, such as disinfection and ultra-filtration processes. Some of important factors that encourage recycling and reuse of wastewaters are the prevention of diversion of water from alternative uses, management of entering water resources and reduction in structural costs [18].

Another factor that encourages reuse is preventing the release of untreated wastewater to the environment. It also helps in giving nutrients to assist the growth of plants for irrigation which is harmful to the ecosystem [19]. Generally, the reuse of urban wastewater are either planned or unplanned. The unplanned is for non-portable uses while the use of treated water for drinking is under the planned direct. The increase in probable risk to public perception is the use of planned direct portable which is very rare. Industrial users, power, hydrocarbon processing, food and beverage are faced with the increase of scarce water resource [20]. Recycled water is the water gotten from industrial and domestic wastewater that has gone through series of treatment and that is allowed for safe use except human consumption.

Recycled water has the benefits of increase in the quantity and quality of available water. With water to increase in quantity, recycled water is now been used by various industries, recreational development centres instead of potable water. Also, diversion from wetlands to other ecosystems is now used. In the case of quality, it is known that recycled water tends to limit the number of nutrients entering water bodies. Untreated wastewater is from washing or bathing and is also a type of wastewater [21, 22]. Some of the challenges faced in the development of efficient wastewater reuse and recycling are pricing strategy and technological. Water is also referred to as a free resource that should be seen and made use of at any given time, therefore when a delivery is made only the service is been paid for which the cost of storage and disposal are ignored [23].

Storage is always a problem if recycled water is not used for domestic use therefore creating solutions that will be needed. The environmental and public health concerns are because the depending on recycling system and these health problems are wastewaters that contain pathogenic microorganisms [24]). Due to these health concerns, such as illness caused by infectious and chemical agents, technology must make sure the use of proper technologies that has gone through series of tests they should also have risk management plan for the construction and implementation. In years to come the world's population 40 percent will face water scarcity and if the discharge off wastewater is not managed it will destroy the surface water and the ecosystem. Revenue source should be planned for reuse such as financing options should be additionally explore. There is a large space between the request and supplies are the next option in developing desalinization and recycling $[25,26]$.

Some other challenges faced are when potable reuse release faeces which are treatment cost, public acceptance and toxicity of the treated produced water. Public acceptance is the greatest obstacle to the reuse of domestic wastewater while technologies have promised to make the standard of drinking water, the issues are the unknown toxic compounds. The main goal of water treatment is to remove waste products from water in such a way that it can meet the standard for consumption. Sewage is wastewater that is from an entire community or residence. Sewage consist of increase in industrial wastes and heavy metals and if not noticed in time and taken care of, these substances are released to the natural environment and causing harm to fragile aquatic organisms [27, 28, 29].

Remediation is the process of reversing environmental damages. There are two main process of remediation they are; chemical and biological remediation. Chemical remediation involves the make use of chemical compounds and methods in the treatment of contaminants. In wastewater treatment, some of these techniques include electron- beam irradiation, chemical extraction and removal by sorption to organoxides [30]. The main aim of biological wastewater treatment is the use of microorganism in removal of organic and inorganic contaminants has improved the efficiency of wastewater treatment to a very large extent. Biological treatments of wastewater are sub- divided into off-site and onsite wastewater treatment systems [6].

In onsite treatment, decomposition of organic waste present in effluents is allowed to soak into the ground unless there is a specific reuse of the water. Onsite systems adopted for wastewater treatment are pit latrine, septic tank and composite latrine [31]. Off-site wastewater treatment is the 
remediation of wastewater that has been conveyed using a sewerage system. Some of the off-site treatment processes include trickling filters, waste stabilization ponds, constructed wetlands, activated sludge and aerated and nonaerated lagoons [32].

Wastewaters are waterborne solids and liquids discharged to the sewers and signify the wastewater of community life. In composition wastewater includes dissolved and suspended unprocessed solids, which are in nature decomposable. Domestic wastewater also contains numerous living organisms, microbes whose existence performance cause the process of disintegration. When decompose proceeds underneath anaerobic surroundings, that is, in the absence of dissolved oxygen in the wastewater, horrible condition effect and odours and unpleasant appearances are formed. When decompose proceeds under aerobic conditions, that is, in the presence of dissolved oxygen, unpleasant situation are avoided and the management method is deeply accelerated [33].

With respect to wastewater, the two general objectives are reduction of community health hazards of a wastewater and elimination of the deteriorative influence of wastewater on receiving water worth and the environment. Although all wastewater has to be disposed of, some are subjected to a variety of types of treatment before disposal while others receive no treatment before disposal. It is argued that wastewater treatment management practices have evolved into a strictly composite body of knowledge based on ancient times practice and useful manufacturing and environmental sciences [34]. The intellectual purpose of these basics goes a long way toward assuring us that the environment will be maintained in a secure and adequate condition.

\section{Conclusion}

This review has been able to examine the issue of wastewater strategies existing to decision makers. While the predictable centralized strategy, developed in the middle of the $19^{\text {th }}$ century and spread out ever since, proved to be very resourceful in pollution control and became the chosen strategy for planners and decision makers, it is progressively predictable that this strategy cannot be viable in many cases. This is mainly due to high costs of transportation systems, especially in low population mass areas and in very poor communities. Low capacities of these communities to implement and manage these services, is another limitation. Due to these, the earlier unwanted strategy of on-site treatment is progressively becoming popular and established. Certainly, knowledge shows that the established centralized wastewater treatment strategy should be complemented with evenly sufficient tools that can provide good solutions for areas where this strategy is not feasible. Improved versions of the traditional on-site technologies and improvement of superior on-site technologies can provide today a viable option for wastewater treatment that can observe with high environmental principles.

In the industrialized countries superior on-site technologies are being introduced successfully to provide solutions to individual farms, small communities, remote facilities, etc. On-site technologies should be measured if they produce high quality effluent in a reasonable price, by low and middle income countries. This paper reviews the main challenges and overview of wastewater reuse and recycling facing decision makers in areas that still require sufficient wastewater treatment, such as small communities in middle income countries.

This review also revealed that due to rapid increase in the level of industrialization and the increment in the population density, domestic and industrial wastewaters are large sources of effluents that are discharged into receiving water bodies and these effluents are the major cause of degradation of the receiving water bodies. Some of the treatment processes used by several wastewater treatment plant are the; chemical remediation, physical remediation or microbial remediation. Most treatment plants are designed to remove nutrients by addition of chemicals or using physical treatment measures. Wastewater management system of a country can't be simply attributed to the presence of guidelines there is the need for appropriate implementation strategies. This can be enhanced through the utilization of systems that are most economically useful and efficient in wastewater treatment.

To guarantee the service desires of planned future development within the city boundaries enough financial support has been focused towards modernization and expansion of the different treatment facilities. Innovation will integrate the use of the best available pollution control technology. The future holds exciting challenges in the wastewater treatment field, which must be met to ensure the protection of our environment.

\section{References}

[1] Environmental Protection Agency (EPA) (2007).Primary, secondary and tertiary treatment. Wastewater Treatment Manuals, Ireland. Published by the Environmental Protection Agency: 11- 100.

[2] Charania SH. (2005). Improving Demand and Supply of Water, 5th edition, pp72 -90, McGraw Hill books.

[3] Kates R, Parris TM and Leiserowitz AA. (2005). What is sustainable development: goals, indicators, values and practice. Environment: Science and Policy for Sustainable Development, 47(3): 9-21.

[4] Joanne MW, Linda MS, and Christopher JW. (2011). Prescott's Microbiology 8, Singapore, and McGraw- Hill Education, pp.539-570.

[5] Metcalf, X. \& Eddy, X. 1999. Advanced Wastewater Treatment: In Wastewater Engineering, Treatment, Disposal and Re-use, 3rd edition. McGraw-Hill New York.

[6] Jegatheesan V, Visuanattan C, and Aim RB. (2008). Advances in biological wastewater treatment. Available at: http://www.faculty.ait.ac.th/visu/.../10/Book Chapter-Final.pdf.

[7] Brooks DB, and Peters R. (2009). Water: the potential for demand management in Canada, Science Council of Canada Discussion Paper. 
[8] Gleick PH, Wolff G, Chalecki E, and Reyes R. (2002).The New Economy of water: The Risks and Benefits of Globalization and Privatization of Freshwater. Pacific Institute for studies in Development, Environment and Security: Oakland.

[9] Biswas AK, Varis O, and Tortajada C. (2004). .Integrated water resource management in South and South-East Asia. Water resources Management Series. Oxford University Press, Oxford.

[10] Christopher, H. (1988). William Dibdin and the idea of biological sewage treatment. Technology and Culture, 29(2): 189- 218.

[11] Levy, Mark A, Esty, Daniel C. (2002).Measuring Nation's Environmental Sustainability. In Environmental Performance Measurement; The Global Report 2001- 2002, Daniel Esty and Peter K. Cornelinus (editors). Oxford University Press, Oxford.

[12] Omer, AAM, Ibrahim, MS, El-Haddad AA and Ali MHM. (2004): Environmental consequences of improper land application of sewage waste water disposal in Sohag, Egypt. Soil and ground water pollution. The Science Conference for Development and Environment in the Arab World, Egypt, March, 23-25.

[13] Yale Centre for Environmental Law \& Policy. (2002). Environmental sustainability index 2001-2002. New Haven.

[14] Marks R. (2003). Development of Australia's largest high quality effluent reuse scheme -Bolivar SA. Proceedings of. 11th IWSA-ASPAC Regional Conference. - Integrating the Urban Water Cycle, Sydney, November 1998, 564-570.

[15] Schmidt WP and Cairncross S. (2007). Household water treatment in poor populations: is there enough evidence for scaling up now? Environmental science \& technology, 43(4): 986-992.

[16] Howard B. (2005).Laundry grey water potential impact on Toowoomba soils -Final Report, the National Centre for Engineering in Agriculture (NCEA).

[17] Fewtrell L, Kaufmann R, Kay D, Enanoria W, Haller L, and Colford JM. (2004). Water, sanitation, and hygiene interventions to reduce diarrhoea in less developed countries: A systematic review and meta-analysis. Lancet Infectious Diseases, 5: 42-52.

[18] Abdel-Jawad M, Ebrahim S, Al-Tabtabei M and Al-Shammari S. (1999). Advanced technologies for municipal wastewater purification: technical and economic assessment. Desalination, 124: 251-261.

[19] Mori A. (1993). Treatment and recycling of sewage sludge in Tokohama. Proceedings of the $15^{\text {th }}$ Federal Convention of Australian water and wastewater Association, pp. 682- 688.

[20] Doran GF, Carini FH, Fruth DA, Drago JA, and Leong LYC. (1997). Evaluation of Technologies to Treat Oil Field Produced Water to Drinking Water or Reuse Quality. Paper SPE 38830 presented at the SPE Annual Technical Conference and Exhibition, San Antonio, Texas, 5-October.

[21] CEPIS/OPS (1996). Calidad del agua: el agua. Centro
Panamericano de Ingeniería Sanitariumsy Ciencias del Ambiente. Available from: http//www.cepis.opsoms.org/eswww/caliagua/el agua.html.

[22] Ringskog K. (1999). Private Sector Participation in Water Supply and Wastewater: Opportunities and Risks. World Bank: Washington D.

[23] Thwaites LA, de Rooij GH, Salzman S, Allinson G, Stagnitti F, Carr R, Versace V, Struck S, March T. (2003). Near-surface distributions of soil water and water repellence under three effluent irrigation schemes in a blue gum (Eucalyptus globules) plantation. Agriculture and Water Management, 86: 212-219.

[24] Hamilton AJ, Boland A, Steven D, Kelly J, Radcliffe J, Ziehrl A, Dillon P, Paulin B. (2005). Position of Australian horticultural industry with respect to the use of reclaimed water. Agricultural Water Management 71: 181-209.

[25] Andrew J. Hamilton AJ, Boland A, Stevens D, Kelly J, Radcliffe J, Ziehrl A, Dillon P and Paulin B..(2005). Position of Australian horticultural industry with respect to the use of reclaimed water. Agricultural Water Management, 71: 181-209.

[26] Muir R. (2006). The economics of recycling. Presentation at the Water Recycling and Infrastructure. Sydney: Synergies Economic Consulting.

[27] Gleick PH. (1993). Water in crisis: a guide to the world's fresh water resources. Oxford University Press, Oxford, pp. 473.

[28] Ahmadun Fl, Pendashteh A, Abdullah LC, Biak DRA, Madaeni SS and Abidin ZZ. (2009). Review of technologies for oil and gas produced water treatment. Journal of Hazardous Materials, 170: 530-551.

[29] Xu J, Song Y, Min B, Steinberg L, and Logan B. (2008).Microbial degradation of per chlorate: principles and applications. Environment Engineering Science, 20(5): 405422.

[30] Rubalcaba A, Suarez-Ojeda ME, Stuber F, Fortuny A, Bengoa C, Metcalfe I, Font J, Carrera J, Fabregat A. (2007). Phenol wastewater remediation: advanced oxidation processes coupled to a biological treatment. Water Science and Technology, 55(12): 221-227.

[31] Klassen A. (2007). Wastewater treatment. Safe Drinking Water Formulation, 12: 1-12.

[32] Klein RD. (1979). Urbanization and stream quality impairment. Water Resources Bulletin, 15(4):948-963.

[33] Wiesmann U. (1994).Biological nitrogen removal from wastewater. Advances in Biochemical Engineering and Biotechnology 51: 113- 154.

[34] Hamby DM. (2000). Site remediation techniques supporting environmental restoration activities - a review. Science of the Total Environment, 191: 203-224.

[35] Frank, Frangano, Carlos Linares, Harold Lockwood, Daniel Rivera, Andrew Trevett, and GuillermoYepes. (2005). Strategic Paper No. 1: Case Studies on Decentralization of Water Supply and Sanitation Services in Latin America. Prepared for the USAID Bureau for Latin America and the Caribbean. Environmental Health Project: Washington, D. C. 